\title{
Conservation of vultures in and around Bandhavgarh Tiger Reserve
}

\section{Sharad Kumar*, Naveen Pandey, Kedar G. Gore, Tahir Ali Rather and Kamlesh Singh Atri}

The Corbett Foundation, Baherakhar, Madhya Pradesh, India

*Corresponding author: sharadtcf@gmail.com

http://dx.doi.org/10.4314/vulnew.v70i1.6

\section{Introduction and rationale}

India has nine species of vulture. Of these, three species - White-rumped Vulture (Gyps bengalensis), Slenderbilled Vulture (Gyps tenuirostris) and Indian Vulture (Gyps indicus) have declined drastically over recent decades. During the mid-1980s India had millions of vultures but drastic population declines between 1996 and 2007 saw $99 \%$ of these vulture populations disappear. Because of such widespread and rapid population declines, all three vulture species were listed as Critically Endangered by the IUCN in 2000 . Prakash (1999) first reported population declines of $>95 \%$ for Gyps vultures in Keoladeo National Park, India, which occurred within a 10 -year period. Subsequent surveys, over the next decade, confirmed very large declines (>96\%) of three Gyps vulture species in India. Similar rapid declines were recorded in Pakistan and Nepa (Gilbert et al. 2006). More recent declines in Egyptian Vulture (Neophron percnopterus) and Red-headed Vulture (Sarcogyps calvus) have also been documented throughout India (Cuthbert et al. 2006).

Veterinary use of diclofenac, a non-steroidal anti-inflammatory drug (NSAID), has been identified as the main cause of the declines of Gyps vultures in South Asia. Diclofenac is toxic to vultures (Oaks et al. 2004; Swan et al. 2006) and is widespread in cattle carcasses across India (Taggart et al. 2007) at sufficient concentrations to be the principal cause of the vulture declines (Green et al. 2006, 2007). Vultures die when they consume a carcass contaminated with diclofenac. Although other reasons such as lack of nesting sites, 
decreases in carcass availability due traditional farming being replaced by mechanical farming and the extensive use of agricultural chemicals exist, these cannot be held responsible for the catastrophic declines. The combined effect of diclofenac and other reasons has pushed these species to the verge of extinction.

In 2006, the governments of India, Pakistan and Nepal banned the veterinary use of diclofenac. Although the manufacture and sale of diclofenac for veterinary purposes is banned, the use of human preparations of diclofenac for livestock treatment is still prevalent. This, compounded with habitat destruction and decreases in carcass availability, is a current concern for remaining vulture populations in India.

Bandhavgarh Tiger Reserve (BTR) is located in the Madhya Pradesh state of India (Map 1). According to the Forest Department in 2010, BTR supported a very good population of vultures and although the rapid assessment of vultures in BTR has been conducted by the Bombay Natural History Society, there is lack of information on the distribution and status of vultures in and around BTR and what threats affect the conservation of vultures. A holistic study with a multiple approach for the conservation of vultures in and around BTR was conceptualized and conducted with the support of the Rufford Foundation.

\section{Objectives of the study}

Bandhavgarh Tiger Reserve harbours four resident vulture species and two migratory vulture species. The current study was designed with the general aim of assessing the status, distribution and conservation of vultures in and around BTR with the following specific objectives:

1. Status and population estimation of vultures in and around BTR

2. Monitoring of roosting and nesting sites

3. Capacity building programme for local veterinary practitioners

4. Awareness creation among local communities

\section{Study Area}

Bandhavgarh Tiger Reserve forms part of the Central Indian Highlands. It is located between the Vindhya and the Eastern flanks of Satpura hill ranges and falls in Umaria, Katni and Shahdol districts of Madhya Pradesh (Map 1). The Reserve lies between 
$23^{0} 27^{\prime} 00^{\prime \prime}$ to $23^{0} 59^{\prime} 50^{\prime \prime}$ North and $80^{\circ} 47^{\prime} 75^{\prime \prime}$ to $81^{0} 15^{\prime} 45^{\prime \prime}$ East. The Protected Area comprises of two conservation units, namely

Bandhavgarh National Park and Panpatha Wildlife Sanctuary. The core area of tiger reserve consists of Bandhavgarh National Park and Panpatha Wildlife Sanctuary (717 $\mathrm{km}^{2}$ ) and the surrounding buffer includes $820 \mathrm{~km}^{2}$, adding up to 1537 $\mathrm{km}^{2}$ as the total area of the reserve.

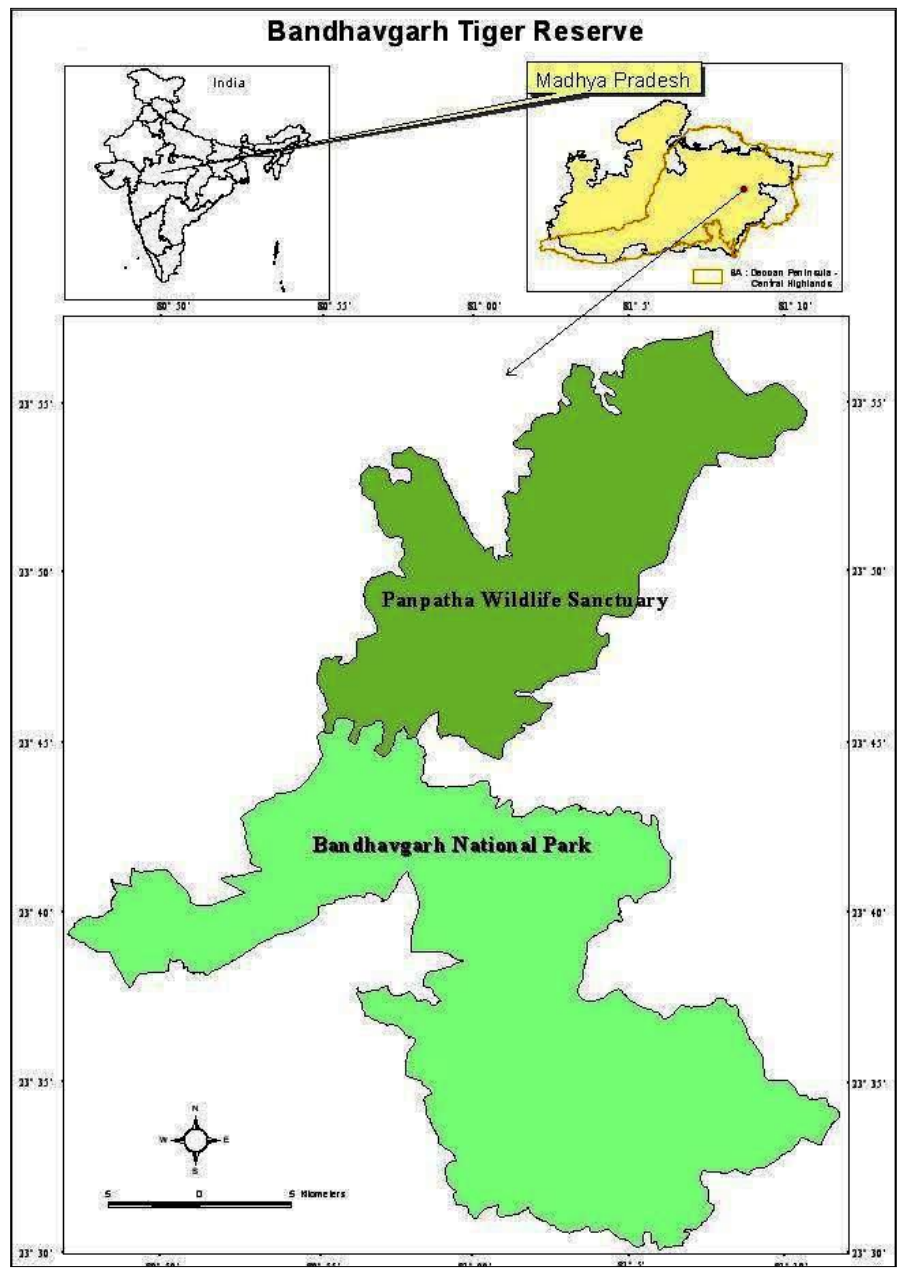

Map 1: Location of Bandhavgarh Tiger Reserve 


\section{Methodology}

\section{Status and population monitoring}

To determine the status and population of the study vulture species, we used road surveys, carcass monitoring, roost counts, nest counts and questionnaire surveys. In road surveys, all vultures observed in flight, on the ground or perched were recorded for species, number of individuals, time, location and activity. Most transects were completed in the morning (0800$1100 \mathrm{hrs})$ and evening (1600$1900 \mathrm{hrs}$ ), when vultures were considered more likely to be active. General weather conditions (clear, partly cloudy, complete cloud cover, rain; wind conditions) were recorded.

Vultures seen on carcasses were recorded and information regarding the location of carcasses came from two sources. Firstly, the carcasses encountered during the road surveys and secondly, the location or presence of carcasses was provided by local villagers. Carcasses were identified to species level and their nature of death was investigated and categorized as either natural or predation. The presence of other avian and mammalian scavengers at carcasses was recorded. Other parameters such as distance from roads, distance from nearest nesting and roosting sites, distance from the nearest water body and age of the carcasses were also recorded. If carcasses were found after vultures had finished feeding and left, questionnaire surveys of locals were carried out in the immediate vicinity to try and assess the number of vultures that had visited the carcass. A brief questionnaire survey was also held with the owners of the deceased animal wherever possible to assess the cause of the death and recent veterinary history of the carcasses.

Roost counts were carried out for Indian Vultures only. Populations of other vulture species in the study area are scattered and no permanent roosting sites were found for the other three vulture species. Roost counts for Indian Vultures were completed in the morning and evening: half an hour before sunrise until all vultures left the roost and the few small numbers of remaining birds could be easily counted. In the evening, vultures in the roost were counted three hours before sunset and arriving vultures were counted until vultures had finished arriving at the roost. To assess the precision of counts, two observers counted vultures simultaneously. 
Previous knowledge provided by forest officials was used to search for nests of all four species. Each cliff was searched for any signs of nests and the traditional nesting areas of White-rumped Vulture were extensively searched; 10 old nests were found. These nests were monitored until the end of March but remained unused.

Information on Egyptian Vultures could not be collected on account of a delay in receiving permission to work in the core area of Bandhavgarh Tiger Reserve, which hosts all the cliffs where this species breeds.

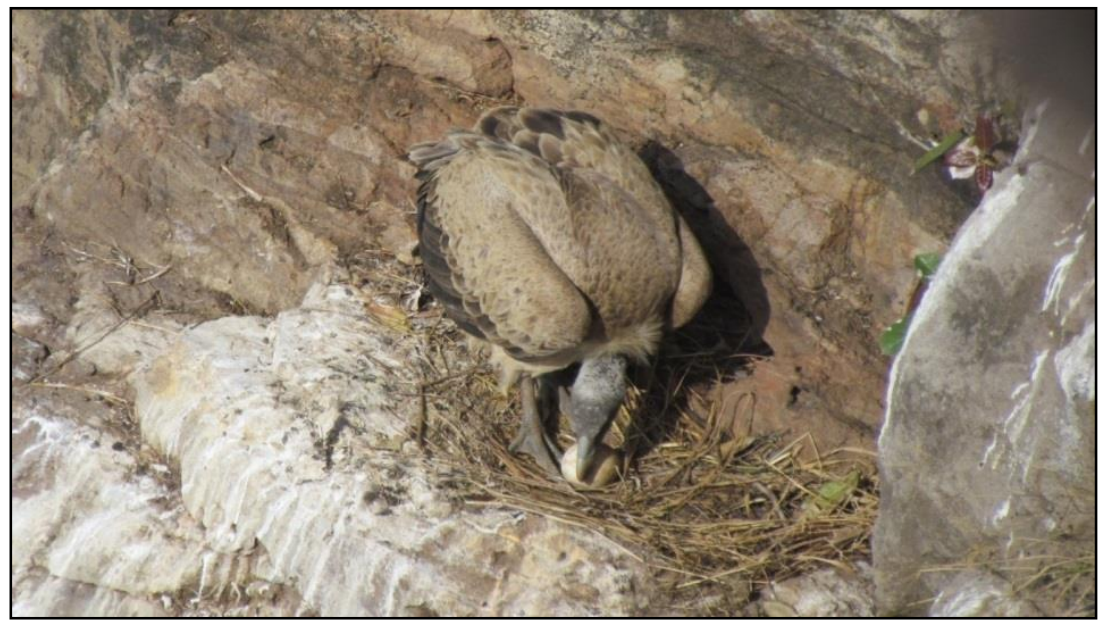

Plate 1: An Indian Vulture at its nest

A questionnaire survey was carried out to determine the opinion of local communities about the past and present status of vultures and their conservation in Bandhavgarh area. The questionnaire survey was conducted in villages located in and around Bandhavgarh Tiger Reserve (BTR). Questionnaires were administered to a sample of 229 households, with the respondents selected randomly.

A similar questionnaire survey was conducted in 76 forest 'beats' with the respective beat guards in eight ranges of BTR to determine the status of vultures. Colour photographs were presented to each beat guard for identification of vulture species and then the 
questionnaire was used to collect information about the presence of vulture roosts and nesting sites in their beats, their past distribution and the habitat used by vulture species in their area.

\section{Breeding behaviour of Indian Vulture}

Observations on breeding behaviour were conducted at all nesting colonies. Between August 2014 and March 2015 vultures were observed for $5 \mathrm{hrs}$ in morning (0700-1200hrs) and $4 \mathrm{hrs}$ in the evening (1400$1800 \mathrm{hrs}$ ) on alternate days. All stages of the breeding season of year 2014-2015 were covered. Individuals and sexes of these large birds are visually indistinguishable in the field, however we recorded the time, duration, and location of copulations, the length of time adults were present at nesting sites and other activities and incidents related to copulation behaviour at each nesting colony. Copulations were recorded both by direct means whereby observers scanned the cliffs with 10x50 binoculars for any mounting event and indirectly by listening to the male's distinctive hoarse call produced when male grips the female's ruff.
Investigation of use of diclofenac and its presence in carcasses

To assess the use of human formulations of the NSAID diclofenac in the treatment of cattle, we conducted meetings with the owners of medical shops and paravets operating in the Bandhavgarh area. The project team visited most of the medical shops located in the Bandhavgarh area and had off-therecord meetings with them. A list of para-vets operating in the Bandhavgarh area was prepared and one-to-one meetings were organized to find out the use of diclofenac in the Bandhavgarh area in treating sick livestock.

\section{Capacity building of local veterinary practitioners}

To enhance the capacity and awareness level of local veterinary practitioners, meetings were conducted with higher authorities of veterinary departments and managers of veterinary colleges to organize workshops and meetings for local practitioners and veterinary students. To increase the impact of workshops in veterinary colleges, we invited Dr. Andrew Hopker from Royal (Dick) School of Veterinary Studies, University of Edinburgh, UK. 
Resource material was developed for organising workshops in veterinary colleges.

\section{Awareness creation among local communities}

Meetings were conducted with school administrators and village headmen to get their support in organising awareness programmes in schools and villages. PowerPoint
Presentations and Quiz contests were developed in the local language to organize awareness programmes in schools and villages. A movie titled "Vanishing Vultures" was screened to highlight information regarding the plight of vultures in India. A large number of posters regarding vulture conservation were developed in English and Hindi. The posters were displayed in local schools and community centres (Plate 2).

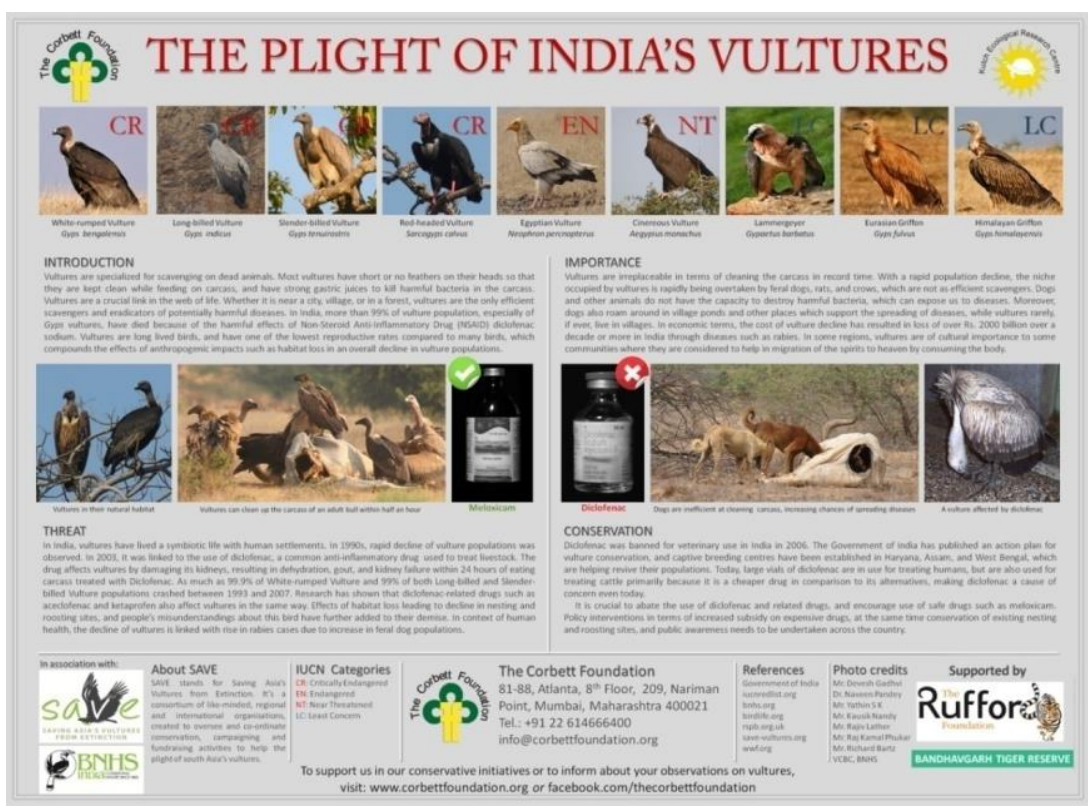

Plate 2: Posters on the plight of India's vultures in English and Hindi 


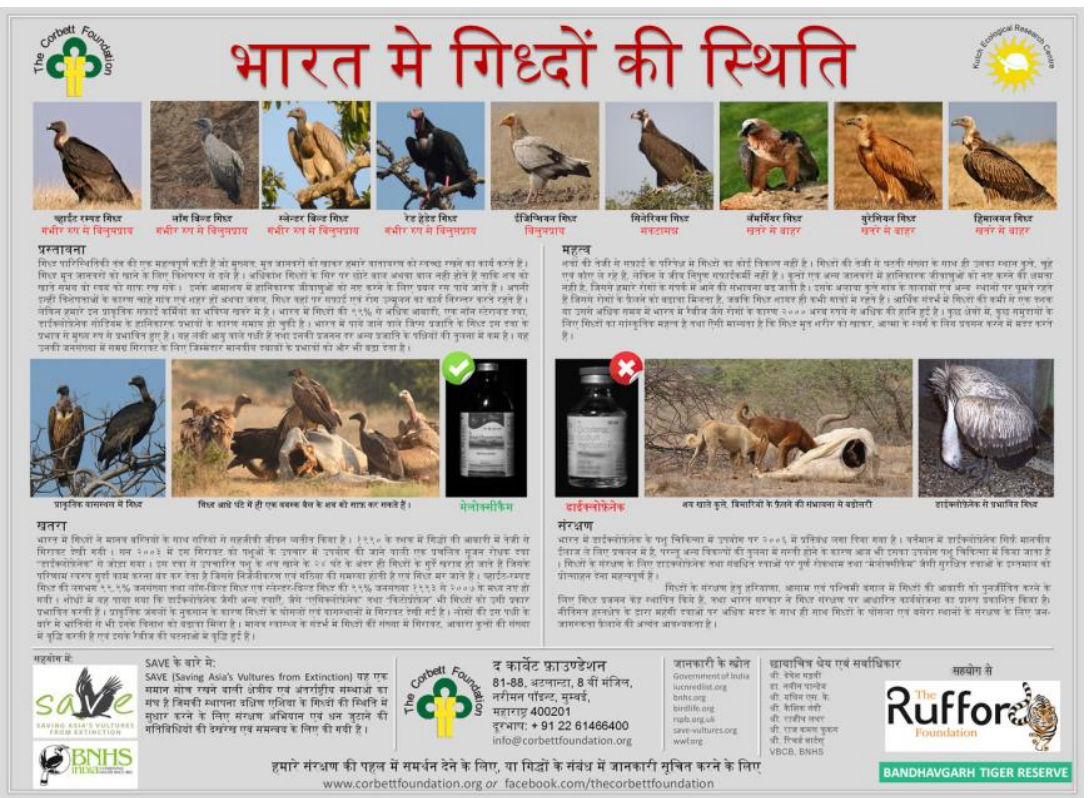

Plate 2 (cont): Posters on the plight of India's vultures in English and Hindi

\section{Results and discussion}

\section{Population estimation}

Based on four different methods employed for assessing the population estimates, the population range of four resident species of vultures in BTR is provided in Table 1. The total vulture population in Bandhavgarh Tiger Reserve is estimated at 520-640 individuals.
During the study period, no roost or nest sites were found in the buffer zone; all were located in the core zone of BTR. Vultures feeding on domestic livestock carcasses formed loose roosting colonies around the immediate vicinity of the carcasses but left for the core zone of BTR as soon as the carcasses were consumed. 
Table 1: Population estimates of resident vulture species in Bandhavgarh Tiger Reserve

\begin{tabular}{|l|l|}
\hline Species & Population Range \\
\hline Indian Vulture & $300-350$ \\
\hline White-rumped Vulture & $120-150$ \\
\hline Egyptian Vulture & $70-90$ \\
\hline Red-headed Vulture & $30-50$ \\
\hline
\end{tabular}

\section{Carcass monitoring}

In total, 31 carcasses were monitored during the study period. Flock size at carcasses was largest for Indian vulture and smallest for Red-headed Vulture (Table 3).

Domestic ungulates formed the majority of carcasses available to vultures compared to wild ungulates (Figure 2). During carcass monitoring, it was observed that vultures faced very intense competition for food from stray or community-owned domestic dogs and Indian Jungle Crows. The dogs were seen dragging vultures away from the carcasses and consumed the entire carcass. This intense competition for food with other scavengers reduces the availability of food for vultures and is likely to have a negative impact on the breeding success of the vultures in the Bandhavgarh area.

Table 3: Total sightings and average flock size of vultures detected on carcasses

\begin{tabular}{|l|l|l|l|}
\hline Species & Total number & Mean & Mean (95\% CI) \\
\hline Indian Vulture & 541 & 17.45 & $17.45 \pm 4.96$ \\
\hline White-rumped Vulture & 222 & 7.16 & $7.16 \pm 2.76$ \\
\hline Egyptian Vulture & 125 & 4.03 & $4.03 \pm 1.30$ \\
\hline Red-headed Vulture & 95 & 3.06 & $3.06 \pm 1.19$ \\
\hline
\end{tabular}




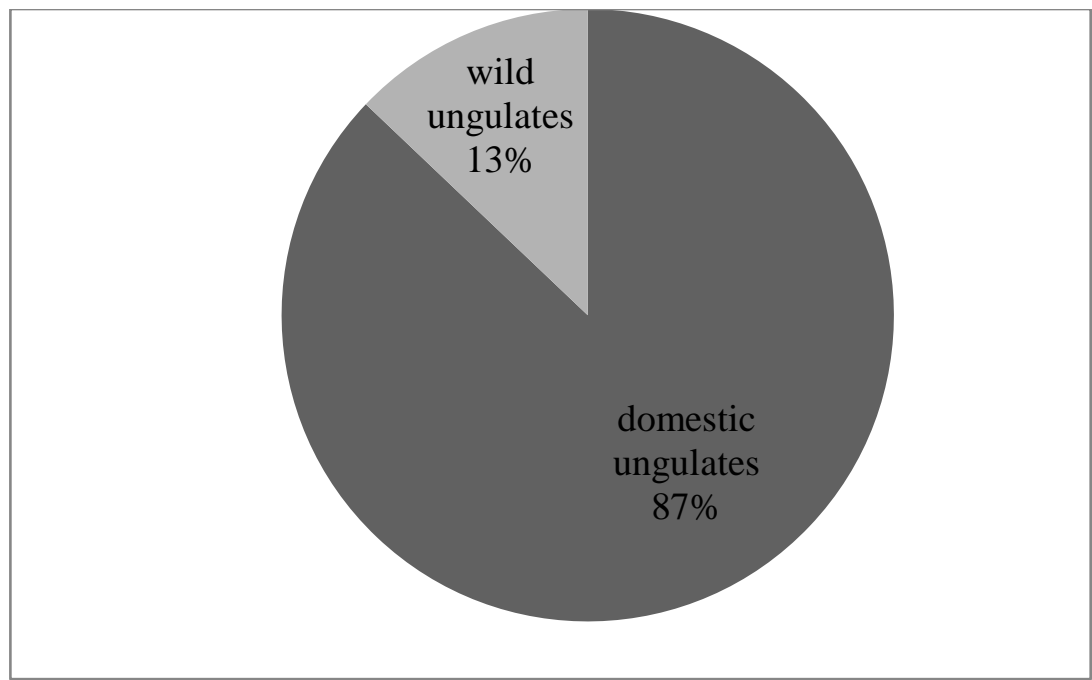

Figure 2: Proportion of carcass in relation of number of wild and domestic species carcass observed

\section{Roost and Nest counts}

Roost counts were used to assess the population status of Indian Vultures. Table 4 provides the mean number of vultures sighted at different roosting sites. Table 5 indicates the number of nests of the four resident species recorded in BTR.

Table 4: Roost count and mean number at various roosting sites in Bandhavgarh Tiger Reserve

\begin{tabular}{|l|l|l|}
\hline Roosting site & Roost counts & Mean (95\% CI) \\
\hline Bathan & 70 & $32.45 \pm 3.34$ \\
\hline Badheni & 41 & $31.78 \pm 3.43$ \\
\hline Natin & 47 & $30 \pm 4.16$ \\
\hline Jhurjhura & 42 & $26.61 \pm 3.32$ \\
\hline Khidki & 36 & $46.55 \pm 5.75$ \\
\hline Crater Hill & 26 & $14.61 \pm 1.54$ \\
\hline Total & $\mathbf{2 6 2}$ & $\mathbf{1 8 2} \pm \mathbf{1 0 . 8 1}$ \\
\hline
\end{tabular}


Table 5: Number of nests found for different species of vulture in Bandhavgarh Tiger Reserve

\begin{tabular}{|l|l|l|l|}
\hline Species & Number of Nests & Nesting Site & Status \\
\hline Indian Vulture & 82 & Cliffs & Successful \\
\hline $\begin{array}{l}\text { White-rumped } \\
\text { Vulture }\end{array}$ & 1 & Trees & Successful \\
\hline Egyptian Vulture & 6 & Cliffs & Successful \\
\hline $\begin{array}{l}\text { Red-headed } \\
\text { Vulture }\end{array}$ & 1 & Trees & Successful \\
\hline
\end{tabular}

Status of Vultures in various forest beats

Out of 76 beats surveyed, 44 beats (58\%) reported vulture sightings. Only a small proportion of the beats had nest and roost sites (16\%). The most common flock size reported by the forest guard was 1-10 vultures (51\%) followed by $10-20$ (36\%) and 20-30 (13\%). Vultures mostly formed small groups and this may be due to competition for the food in the study area.

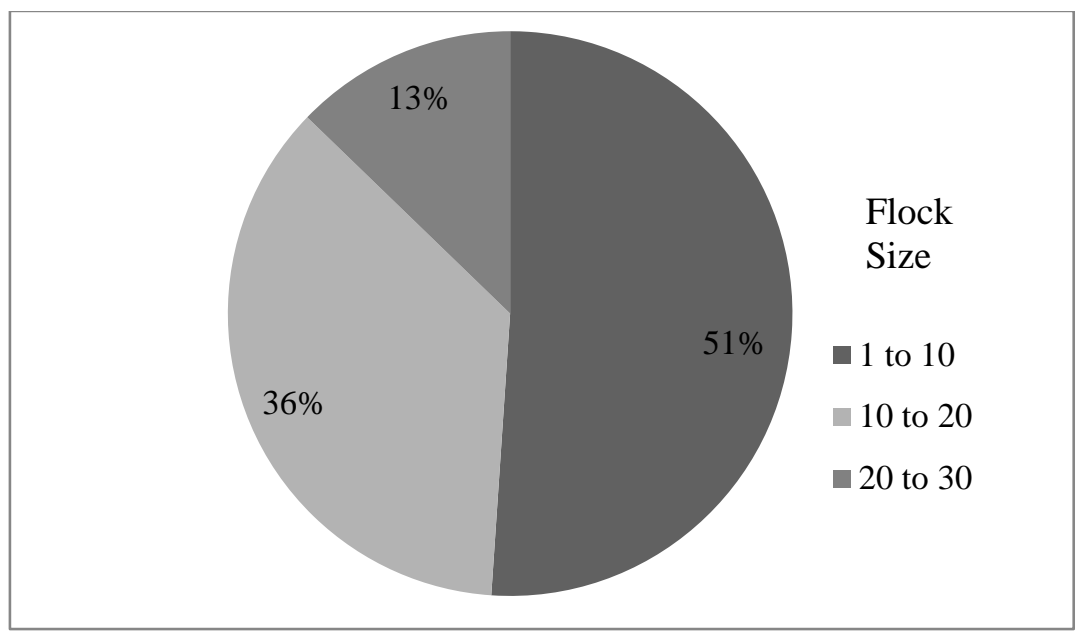

Figure 4: Percentage occurrence of various flock sizes of vultures reported by Forest Guards 
People's perceptions about the status of vultures and their conservation

Out of the 229 respondents interviewed using questionnaires, $86 \%$ were male and $14 \%$ were female. About $68 \%$ of the respondents were engaged in farming and agricultural practices and other small temporary jobs as drivers or working at local resorts, while 33\% of the respondents constituted of students belonging to three categories viz. $10^{\text {th }}$ grade $(21 \%), 12^{\text {th }}$ grade $(9 \%)$ and graduate $(3 \%)$, (Table 6).

The most frequently sighted (55\%) flock size of vultures was 510 and dumping sites had the highest frequency $(79 \%)$ of sighting vultures (Table 7). About $51 \%$ of the respondents had sighted vultures feeding on carcasses, $36 \%$ of the respondents sighted vultures while flying only and $12 \%$ of the respondents had sightings both while feeding and flying. A large proportion of respondents (91\%) was aware of the catastrophic vulture declines, but most people were unaware of the reasons. When asked about the reasons responsible for population drop, $21 \%$ of respondents answered that some chemical drug was responsible for the vulture population decline but they did not know the name of the drug and had never heard of diclofenac in the past. Awareness of diclofenac toxicity to vultures was seriously lacking among the local communities: only $13 \%$ of respondents had a slight idea that the drug is responsible for the steep decline of vulture populations.

Dumping of carcasses in open areas remains the prevalent carcass disposal practice $(94 \%)$ while only a small proportion $(6 \%)$ adopted the burial practice. Permanent dumping sites were lacking and random disposal of carcasses was adopted by most $(81 \%)$ of the respondents. Approximately $60 \%$ of respondents considered vultures as sacred and $90 \%$ of the respondents replied in the affirmative when asked to join vulture conservation programs. Only $12 \%$ of the respondents had seen vulture nests in their areas. A large proportion of respondents $(82 \%)$ had veterinary facilities available while $18 \%$ of the respondents relied on traditional treatment of livestock. 
Table 6: Gender and educational level of respondents

\begin{tabular}{|l|l|}
\hline Contents & Results \\
\hline Male respondents & $\mathbf{8 6 \%}$ \\
\hline Female Respondents & $\mathbf{1 4 \%}$ \\
\hline Respondents engaged in farming and other small jobs & $\mathbf{6 9 \%}$ \\
\hline Tenth grade respondents & $\mathbf{2 1 \%}$ \\
\hline Twelfth grade respondents & $\mathbf{9 \%}$ \\
\hline Graduate respondents & $\mathbf{3 \%}$ \\
\hline Total student Respondents & $\mathbf{3 3 \%}$ \\
\hline
\end{tabular}

Table 7: Details of questionnaire surveys held with villagers

\begin{tabular}{|l|l|}
\hline Contents & Results \\
\hline Percentage of respondents aware of population drop & $\mathbf{9 1 \%}$ \\
\hline Percentage of respondents aware of diclofenac & $\mathbf{1 3 \%}$ \\
\hline $\begin{array}{l}\text { Percentage of respondents dumping carcass in open fields } \\
\text { randomly }\end{array}$ & $\mathbf{9 4 \%}$ \\
\hline Percentage of respondents adopting burial practices & $\mathbf{6 \%}$ \\
\hline Percentage of respondents having veterinary facilities & $\mathbf{8 2 \%}$ \\
\hline $\begin{array}{l}\text { Percentage of respondents adopting traditional treatment } \\
\text { of livestock }\end{array}$ & $\mathbf{1 8 \%}$ \\
\hline Percentage of respondents who had sighted nests & $\mathbf{1 2 \%}$ \\
\hline $\begin{array}{l}\text { Percentage of respondents who claim to sight vulture only } \\
\text { at carcass or dumping sites }\end{array}$ & $\mathbf{7 9 \%}$ \\
\hline $\begin{array}{l}\text { Percentage of respondents willing to conserve Vultures } \\
\text { and participate in awareness and conservation programs }\end{array}$ & $\mathbf{9 0 \%}$ \\
\hline
\end{tabular}




\section{Breeding behaviour}

The majority $(89 \%)$ of observed copulations were considered successful while $9 \%$ of the copulations were regarded as unsuccessful; $2 \%$ were unclassified. Mean duration of copulations was 24 \pm 1.38 seconds (range 50 seconds). Copulations had a bimodal prior to egg-laying. Both adults were distribution with peaks in the observed to share parental roles. morning and evening (Figure 5).
Copulation was most frequently observed in September and October and coincided with nest-building behaviour (Figure 6). Peak egglaying occurred during November although some eggs were detected in October. The first observation of copulation and nest-building behaviour was made two months

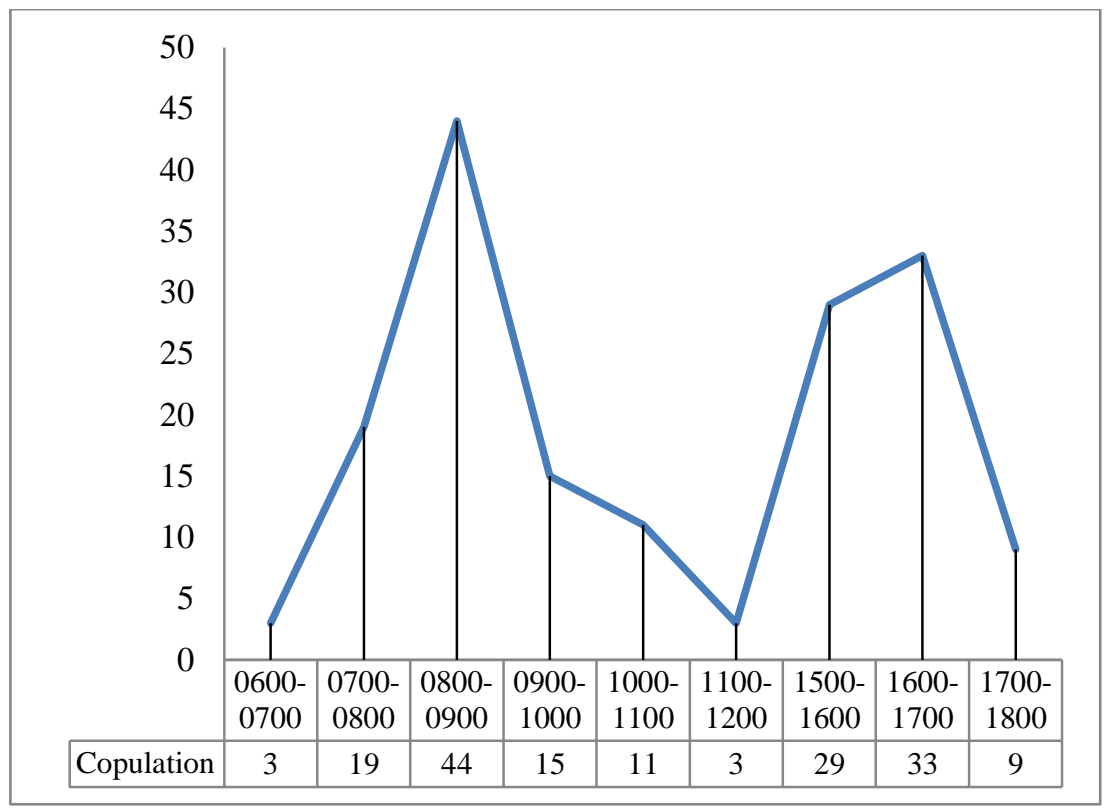

Figure 5: Temporal distribution of copulations for Indian Vulture 


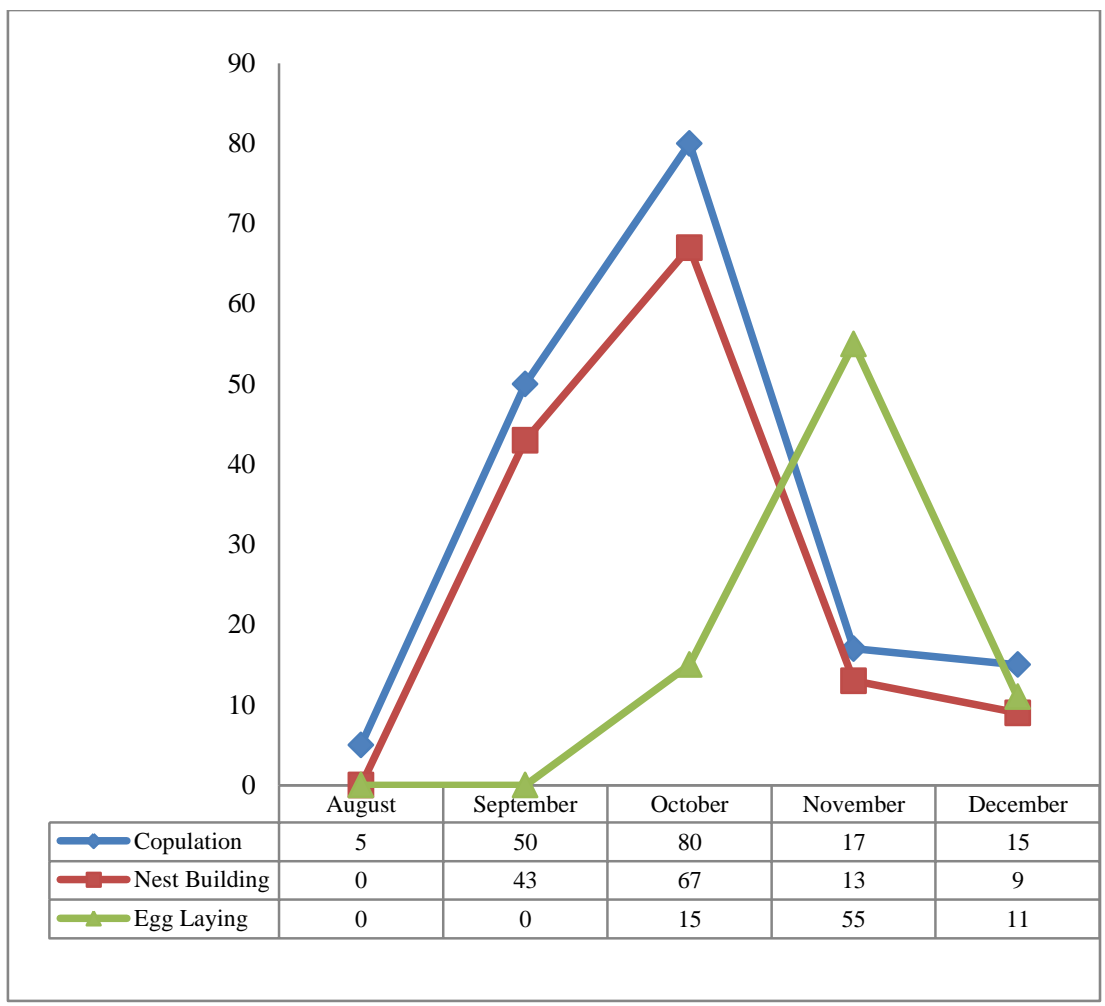

Figure 6: Temporal distribution of copulation, nest-building and egg-laying of Indian Vultures in Bandhavgarh Tiger Reserve

The first chicks were observed at fledged at the end of March. The Khidki nesting site on December 30, total number of chicks seen flying or 2014. Based on plumage leaving nests was not observed on characteristics of the chick, the age account of the completion of project was estimated to be approximately 10 days. By March 2015, all nests had produced chicks. The first chicks and termination of permission to visit core area of the Bandhavgarh Tiger Reserve. 


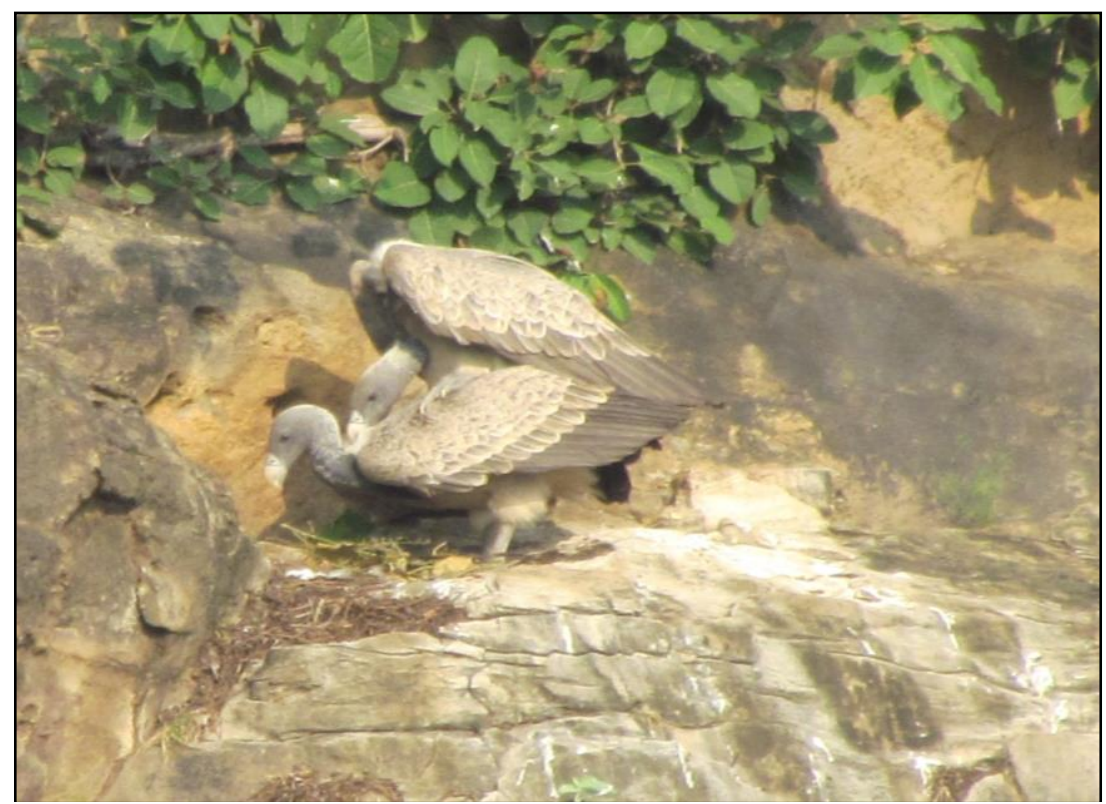

Plate 3: Copulation of Indian Vulture in Bandhavgarh Tiger Reserve

\section{Threat assessment}

\section{Use of diclofenac by para-vets}

Based on meetings held with chemists and para-vets operating in the Bandhavgarh area, it was found that people still used human preparations of diclofenac for the treatment of cattle. The major reason behind the use of diclofenac by paravets is that the drug is cheaper than meloxicam and it is faster acting in the recovery of animals. When requested not to sell or use the human diclofenac for veterinary purpose, their answers were not supportive and most of them declined our request, justifying the selling of human NSAID diclofenac for the veterinary use on the basis of profits and their ignorance towards the harmful impacts of diclofenac on vultures.

\section{Poisoning and direct persecution}

No case of poisoning or direct persecution was recorded or observed in Bandhavgarh during the study period. Although one dead Indian Vulture was found in a village located at the border of the protected area. Based on a rapid assessment by 
the research team and information received from villagers, it was found that vulture had fallen off the tree which was temporarily used as preroosting site. Post-mortem examination carried out by the Forest Department revealed that vulture had died of dehydration, although autopsy did not reveal any incidence of diclofenac consumption.

\section{Food availability}

Based on field surveys, 31 carcasses were located during the study, indicating an average availability of 2.58 carcasses every month. Most of the carcasses encountered during surveys were domestic ungulates and relatively small percentage of wild ungulate carcases was encountered.

Disturbances to Nesting and Roosting sites

All nesting and roosting sites of Indian Vultures were found inside the core area of the Bandhavgarh Tiger Reserve and were protected from adverse human interference. All roost sites of White-rumped and Red-headed Vultures were temporary and although mixed flocks of all four vulture species did roost near the carcasses overnight, the same sites were not used again once the carcass was consumed. No permanent roosting site of Whiterumped Vulture, Red-headed Vulture and Egyptian Vulture was recorded in the study area.

Competition with other scavenging species

During the study period, on all carcasses, we have recorded 541 observations of Indian Vulture, 222 of White-rumped Vulture, 95 of Redheaded Vulture and 125 of Egyptian Vulture. Additionally there were 458 observations of crows, 92 of feral dogs and 11 of jackals. The high number of crows is significant in that crows not only compete with vultures on carcasses but also chase them away. Vultures were regularly pecked by crows and chased away from carcasses, but if the number of vultures exceeded the number of crows at a carcass, then the vultures would out-compete the crows. Vultures face additional competition from feral dogs. Dogs dominate vultures at a carcass and, additionally, usually do not leave a carcass but stay nearby and prevent any vultures from landing in the area. Dogs also consume large amounts of a carcass, thus reducing food availability for vultures. Other scavengers, such as jackals and wild 
boars, did visit carcasses but their negligible. interference was considered

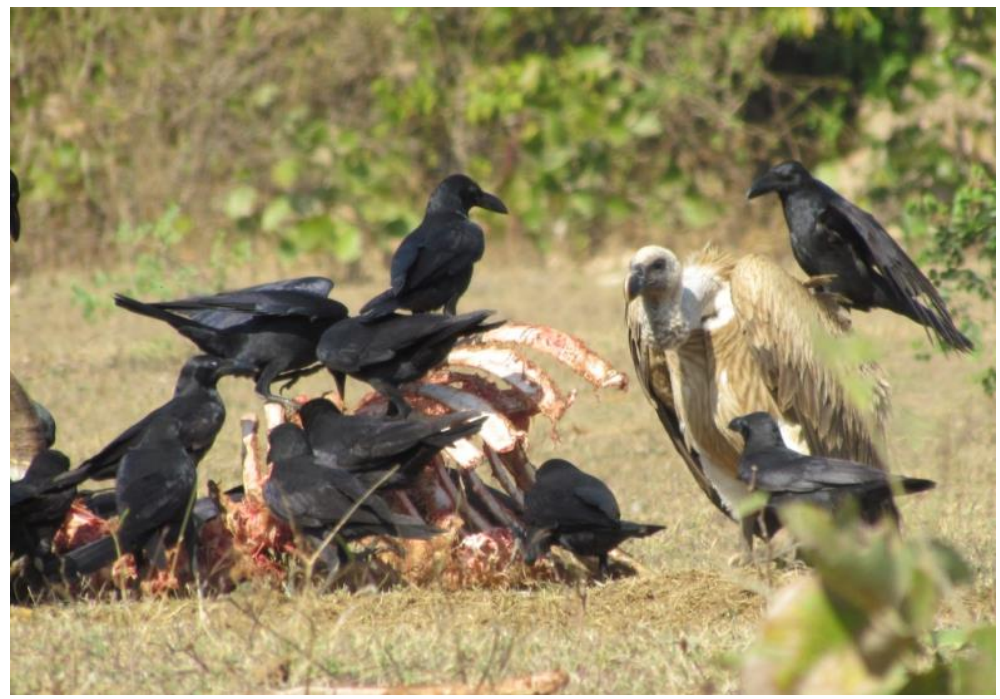

Plate 4: Crows pecking vultures to chase them away from the carcass

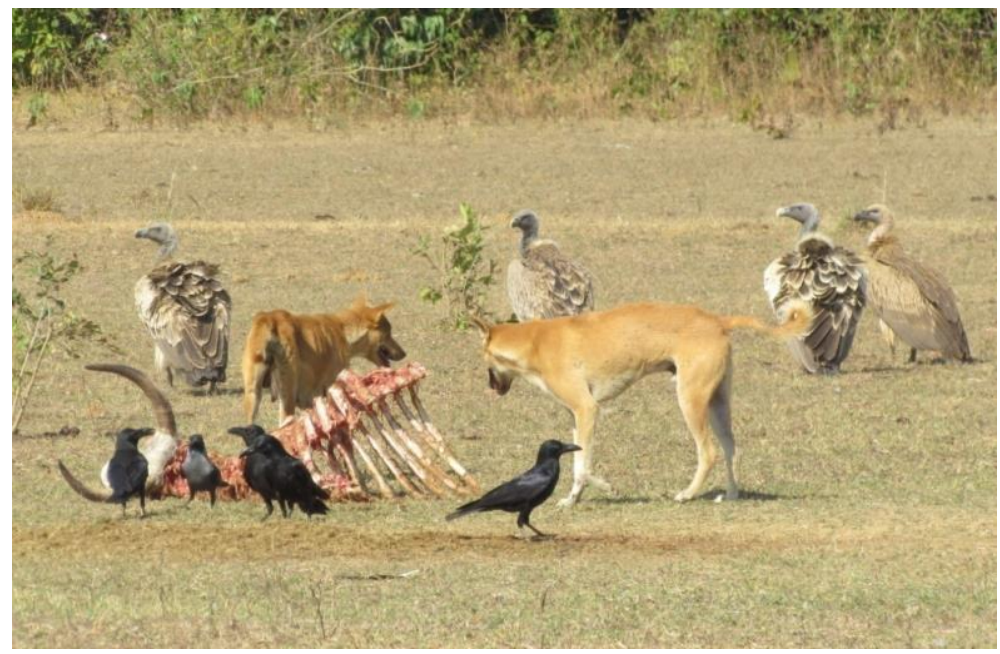

Plate 5: Dogs keeping vultures away vultures from a carcass 
Capacity building of local vet practitioners

To build the capacity of veterinary practitioners in Bandhavgarh area, two meetings were organized with veterinarians operating in the area. The meetings discussed the importance of vulture conservation, the drastic decline in their populations, the role of diclofenac in wiping out vulture populations and how they could help the conservation of vultures. Additionally, ten meetings were organized with paravets operating in the Bandhavgarh area. At these meetings, information was provided on the plight of vultures and a request for their support in vulture conservation was made. The para-vets were informed about the fatal effects of diclofenac on vultures and availability of a safer drug, meloxicam, for treating cattle. At the end of the meeting, meloxicam was distributed to participants to promote its use in the treatment of livestock. To increase the capacity of future vets, three workshops were conducted in three veterinary colleges: the Veterinary College at Rewa, the Apollo College of Medicine at Jaipurand and the College of Veterinary Science at Proddatur. During these workshops, information was again provided about the plight of vultures and the negative impact of diclofenac on vulture populations, in addition to a request for the support of future veterinary surgeons in vulture conservation.

In the workshop conducted in the Veterinary College of Rewa, Dr Andrew Hopker, Lecturer in Farm Animal Practice, The Royal (Dick) School of Veterinary Studies, University of Edinburgh, UK provided detailed information about various pain-killers used in the veterinary treatment and their impact on the vulture conservation. He also briefed the group about the various environmental issues involved in the use of various pain-killers. 


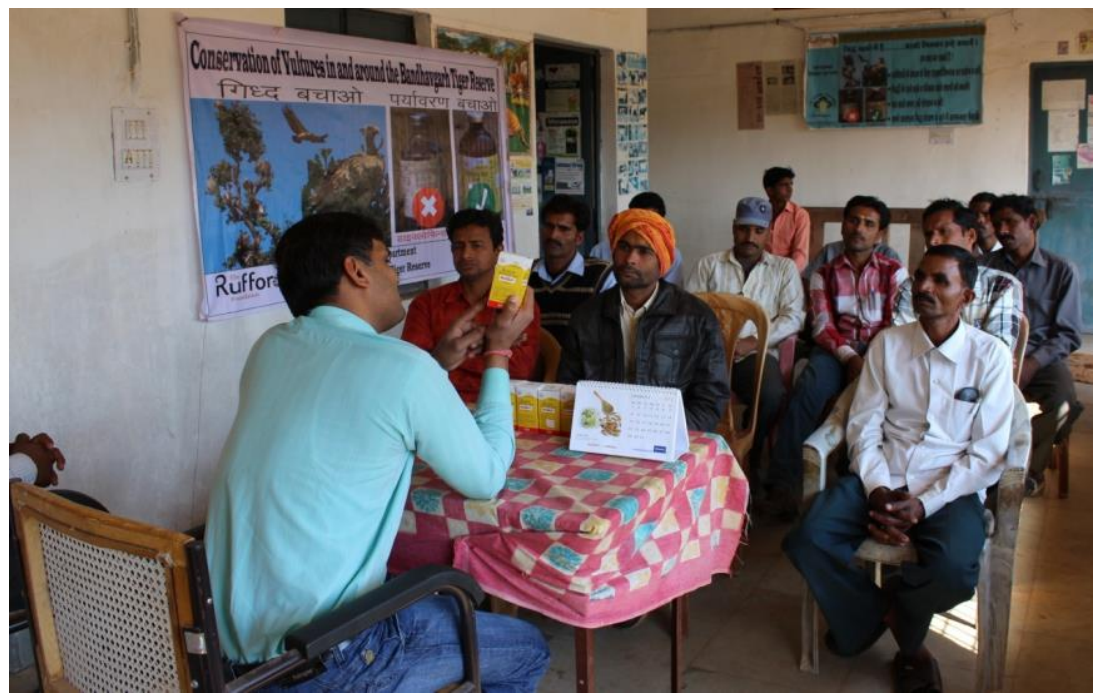

Plate 6: Project team promoting use of meloxicam (alternative safer drug)

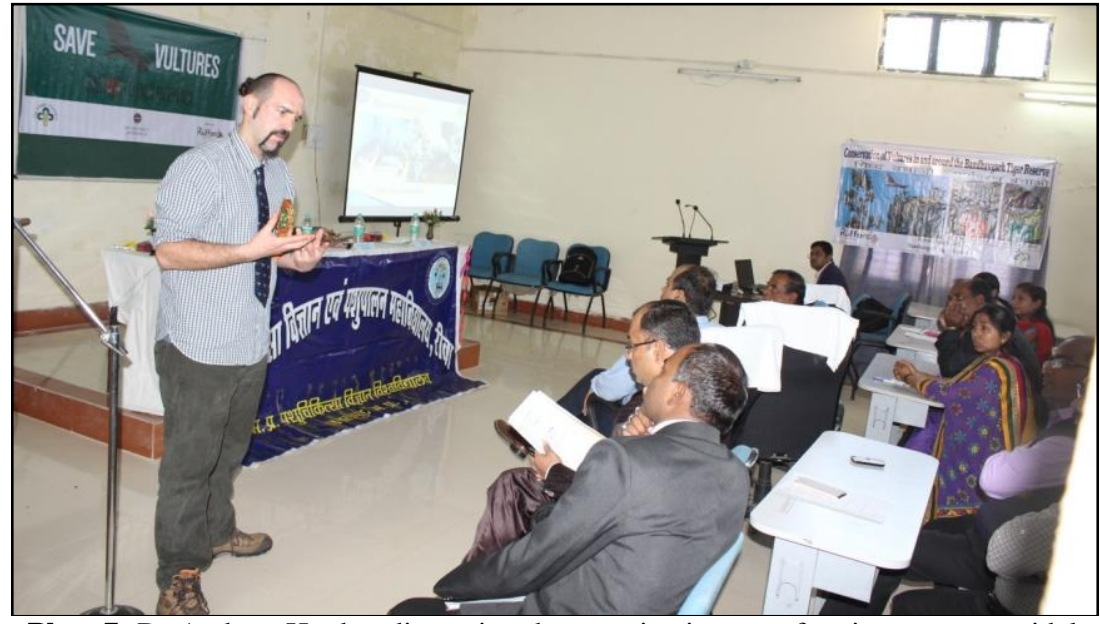

Plate 7: Dr Andrew Hopker discussing the negative impact of various non-steroidal drugs on vultures 
Conservation campaigns in villages and schools

To increase understanding of local communities about the importance of vulture conservation, awareness programmes were organized in 31 villages. Awareness programmes included the exhibition of vulture posters, PowerPoint presentations and documentaries on vultures in the local language. A vaccination programme for domestic livestock was launched in collaboration with the Forest Department, for villages located in and around the Bandhavgarh Tiger Reserve. During this programme, villagers were again made aware of diclofenac and its catastrophic impact on vultures. Vulture posters were exhibited and distributed among villagers and an electronic media campaign for vulture conservation was made by mounting a loud speaker on vehicle.

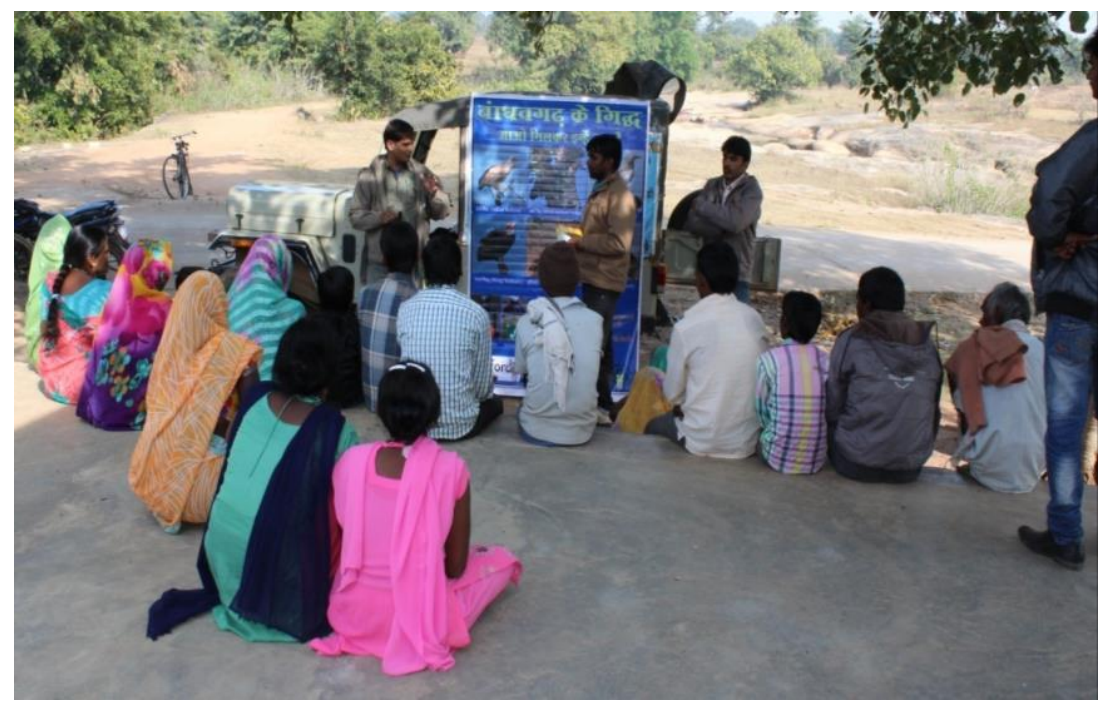

Plate 8: Project team discussing the plight of India's vultures with villagers

Similar awareness campaigns were carried out in 20 schools for students aged 12-15 years. Quiz competitions and painting competitions were used to increase the involvement of students in awareness programmes. Road-rallies were held on several occasions with hand-held vulture posters emphasizing their conservation. The local Forest 
Department was actively involved in all of the conservation and awareness campaigns. General information about the status of vultures, their role as scavengers, causes of their population decline and the toxicity of diclofenac was all imparted to the students participating in the awareness campaigns. Students were also urged to convince their parents to stop the use of diclofenac for treating livestock. Winners of the quiz or painting competitions were given awards and certificates of participation to encourage them to join conservation efforts. The students pledged their support for vulture conservation and promised to spread the conservation message among their friends, family members, neighbours and relatives.

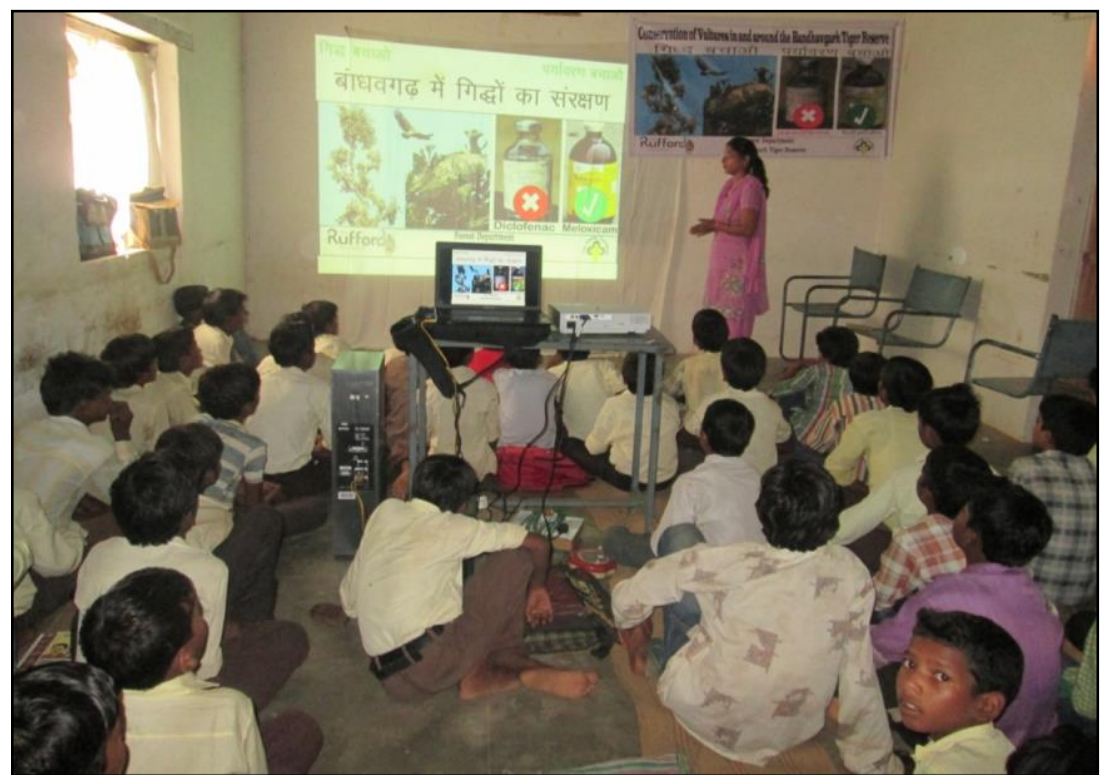

Plate 9: Vulture awareness programmes in the schools 


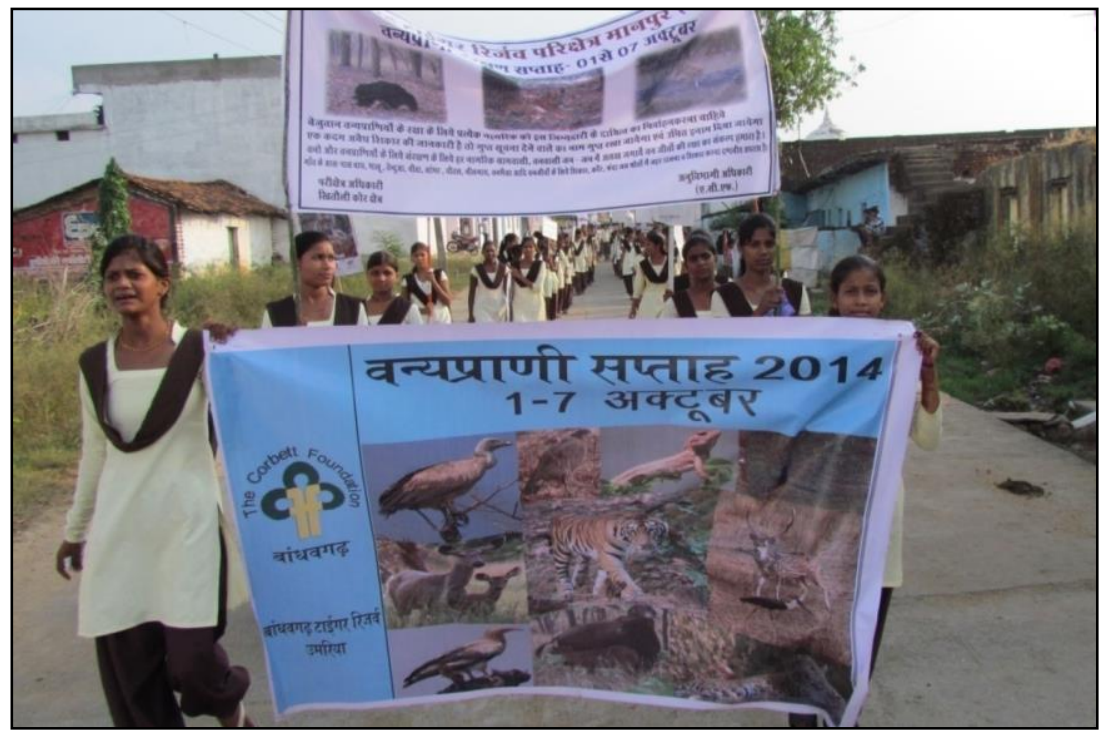

Plate 10: A rally to create awareness about vultures and other wildlife species

\section{Conclusions and recommendations}

\section{Vulture Safe Zone}

Bandhavgarh Tiger Reserve supports a very good population of vultures and to ensure long-term conservation of vultures in the area, it is crucial to create a Vulture Safe Zone around the Bandhavgarh Tiger Reserve. To create the Vulture Safe Zone in Bandhavgarh area, ongoing programmes aimed at discontinuation of diclofenac should be expanded to villages located within a radius of $100 \mathrm{~km}$ from the boundary of the core zone of
Bandhavgarh Tiger Reserve. To discontinue the use of diclofenac it is also necessary to involve the Veterinary Council of India to issue a circular for the veterinary practitioners to observe a complete ban on the use of diclofenac in the treatment of livestock.

\section{Spay- Neuter programme}

The vulture population in Bandhavgarh area is facing intense competition for food from stray and feral dogs and this population of dogs is increasing continuously. Stray dogs are a threat to the long- 
term conservation of vultures in the area. To control the population of the stray dogs, we recommend that a spay-neuter programme is initiated in Bandhavgarh Tiger Reserve. In the first phase, the spay-neuter programme should be initiated in the villages located in the core zone of Bandhavgarh Tiger Reserve, as the dogs in these villages have the highest chance of disturbing vultures.

\section{Conservation education}

The villagers in Bandhavgarh are friendly towards vulture conservation but they lack awareness of diclofenac and its toxicity to vultures. There is also a need for increased awareness of dumping practices and avoiding disturbance to vultures while they are feeding on domestic and wild ungulates. Local administrative bodies like Panchayats can be involved and made responsible for the safe disposal of carcasses for vultures. Media personalities can be also involved to highlight the importance of vultures and their ecological role. Regular and active awareness campaigns are likely to be effective, especially in protected areas, which are visited by large numbers of tourists every year. Vulture posters highlighting the declines and their decreasing population trend should be posted at the appropriate sites for observation by tourists.

\section{Annual monitoring of vulture population}

Most of the forest beats interviewed have active vulture sightings and the frequency of such sightings increases greatly when kills are made available either by predation or the natural death of wild ungulates. Such kills, or leftovers from predator kills, can be made available to the vultures in a controlled way by establishing feeding points. In most cases, kills are not available to vultures due the forest department guarding kills to ensure carcasses are not poisoned by poachers or villagers trying to kill tigers. Carcass remains are usually buried for the same reasons. Such practices need to be modified, at least for some time if not forever, to ensure that diclofenac-free carcasses are available to vultures.

Annual population surveys, especially for vultures, can be conducted by Forest Department personnel. Monitoring nesting, recruitment, survival, carcass availability etc. can be achieved with the participation of active NGOs operating in the area. 
Providing a subsidy on meloxicam for para-vets

To ensure complete elimination of the misuse of diclofenac in veterinary treatment, a subsidy on meloxicam for Livestock Inspectors (Paravets) working in the buffer zone of Bandhavgarh area should be provided by conservation agencies. This initiative can be undertaken in association with pharmaceuticals companies.

Bandhavgarh Tiger Reserve has good vulture population consisting of three critically endangered and one globally endangered vulture species in comparison to other protected areas in India. Bandhavgarh also hosts two migratory vulture species. Proper management and conservation strategies need to be formulated and implemented to make Bandhavgarh as one of the first protected areas which can sustain large populations of vultures in the wild.

\section{Acknowledgements}

We are extremely grateful to the Rufford Foundation for financial support to carry out this study in the Bandhavgarh Tiger Reserve. We are extremely grateful to Mr. Dilip D.
Khatau and Rina Khatau for their support in implementation of this project. The study would not have been possible without the kind permission of Mr. Narendra Kumar, Chief Wildlife Warden and Principal Chief Conservator of Forest (Wildlife) Madhya Pradesh and Mr. C. K. Patil, Chief Conservator of Forest (Wildlife).

We wish to thank to Mr. Sudhir Kumar, former Director, Mr. C.H. Murlikrishanan, Director and Mr. S. C. Gupta, Deputy Director, Bandhavgarh Tiger Reserve for their generous help and support in implementation of this project in field. We are thankful to the Department of Wildlife Sciences, Aligarh Muslim University, Aligarh, Dr. Jamal Ahmad Khan, for providing guidance during the study.

We wish to thank Dr Andrew Hopker, Lecturer in Farm Animal Practice, The Royal (Dick) School of Veterinary Studies, University of Edinburgh, UK for providing support in organizing workshop in the veterinary colleges.

We extend our great appreciation towards Ramsajeevan Baiga, Rajendra Prasad, Shiv Kumar Minj, Santosh Barman, Sudama Yadav, Dalbeer Singh, Dr. Gyanendra Prajapati, Ashok Bhatt, Manoj Chaundiyal, Ramcharan Jayaswal, 
Deepchandra Pal, Pappu Yadav and Durgesh Yadav.

\section{About The Corbett Foundation}

The Corbett Foundation (TCF) was established on the Earth Day (22 April) of 1994 by Mr. Dilip D. Khatau, a well-known industrialist, a former Member of the National Board for Wildlife in India, and a Member of Indian Wildlife Business Council of Confederation of India Industry. TCF is a non-profit, nongovernmental organization fully dedicated to the cause of conservation of wildlife species such as the Tiger Panthera tigris. TCF's Mission Statement says, "The Corbett Foundation consists of a group of dedicated men and women who are committed to the conservation of wildlife and nature, and fulfilling the ambition that human beings and nature must live together in harmony." TCF strongly believes that conservation requires a multi-faceted approach, and hence it is actively involved in conservationoriented research, facilitating advocacy campaigns, spreading environmental awareness, providing primary healthcare for forestdependent communities and engaging in tribal welfare through vocational and livelihoods training and sustainable development initiatives. Apart from being a member of the International Union for Conservation of Nature (IUCN) and a Member of the Global Tiger Forum, TCF is also an activity partner with the United Nations Decade on Biodiversity, The Ramsar Convention and the Born Free Foundation. TCF has been accredited by Credibility Alliance under the Desirable Norms for Voluntary Organisations in India.

\section{References}

Cuthbert, R., R.E. Green, S. Ranade, S. Saravanan, D.J. Pain, V. Prakash, and A.A. Cunningham (2006). Rapid population declines of Egyptian Vulture (Neophron percnopterus) and Red-headed Vulture (Sarcogyps calvus) in India. Animal Conservation 9: 349-354.

Gilbert, M., R.T. Watson, M.Z. Virani, J.L. Oaks, S. Ahmed, M.J.I. Chaudhry, M. Arshad, S. Mahmood and A.A. Khan (2006). Rapid population declines and mortality clusters in three Oriental white-backed vulture Gyps bengalensis colonies in Pakistan due to diclofenac poisoning. Oryx 40: 388-399. 
Green, R.E., M.A. Taggart, D. Das, D.J. Pain, C. Sashikumar, A.A. Cunningham and R. Cuthbert (2006). Collapse of Asian vulture populations: risk of mortality from residues of the veterinary drug diclofenac in carcasses of treated cattle. Journal of Applied Ecology 43: 949-956.

Green, R.E., M.A. Taggart, K.R. Senacha, B. Raghawan, D.J. Pain, Y. Jhala and R. Cuthbert (2007). Rate of decline of the Oriental White-Backed Vulture population in India Estimated from a Survey of Diclofenac Residues in Carcasses of Ungulates. PLoS ONE 2(8): e686

Oaks, J.L., M. Gilbert, M.Z. Virani, R.T. Watson, C.U. Meteyer, B.A. Rideout, H.I. Shivaprasad, S. Ahmad, M.J.I. Chaudhry, M. Arshad, S. Mahmood, A. Ali, and A.A. Khan (2004). Diclofenac residues as the cause of population decline of vulture in Pakistan. Nature 427: 630-633.

Prakash, V. (1999). Status of vultures in Keoladeo National Park, Bharatpur, Rajasthan, with special reference to population crash in Gyps species. Journal of Bombay Natural History Society 96: 365-378.

Taggart M.A., K.R. Senacha, R.E. Green, Y. Jhala, B. Raghavan, A.R. Rahmani, R. Cuthbert, D.J. Pain and A.A. Mehrag (2007). Diclofenac residues in carcasses of domestic ungulates available to vultures in India. Environment International 33: 759-765

Taggart M.A., K.R. Senacha, R.E. Green, R. Cuthbert, Y. Jhala, A.R. Rahmani, A.A. Mehrag, M. Rafael and D.J. Pain (2009). Analysis of nine NSAIDs in ungulate tissues available to Critically Endangered vultures in India. Environment Science and Technology 43: 4561-4566. 